\title{
AS FORMAS DISCURSIVAS E A AMEAÇA COMUNISTA
}

\author{
Bethania Mariani* \\ $\mathrm{UFF} / \mathrm{CNPq} / \mathrm{LAS}$
}

Resumo: A partir do arcabouço teórico da Análise do discurso, considerando, sobretudo, o conceito de formas discursivas remissivas (PÊCHEUX, 1969), objetiva-se depreender e analisar os processos de produção de sentidos para as palavras comunismo, comunista e esquerda na discursividade política brasileira, tal como estão circulando na mídia social.

Abstract: From the theoretical perspective of Discourse Analysis, considering particularly the concept of remissive discoursive forms (PECCHEUX, 1969), we intend to detect and analyse the processes of meaning production involved in the use of the words comunismo (communism), comunista (communist) and esquerda (left) in Brazilian political discourse, such as they are circulating in social midia.

\section{Introdução}

No Brasil, sobretudo nos últimos três ou quatro anos, as palavras comunismo e comunista deixaram de circular ligadas a siglas de partidos políticos institucionalmente estabelecidos, cujo funcionamento se encontra democraticamente assegurado desde a promulgação da Constituição de 1989. Associadas a críticas exacerbadas e frequentemente determinadas com adjetivações de baixo calão, as palavras comunismo e comunista, assim como esquerda (como hiperônimo) circulam de maneira célere, sobretudo em redes sociais (blogs, twitter, instagram e whatsapp), principalmente naquelas que divulgam discursos políticos vinculados às posições de poder neoliberais e de extrema direita vigentes a partir das eleições presidenciais de 2018. As palavras comunismo, comunista (c) EY-NC-SA

Líng. e Instrum. Linguíst., Campinas, SP, n. 44, p. 270-289, jul./dez. 2019 
e esquerda foram progressivamente deslocadas do campo específico de debate sobre ideias políticas e, como efeito, produziu-se um forte movimento para o silenciamento de ideias sobre sociedade e sobre economia formuladas na ordem do discurso materialista. Em função deste deslocamento e ressignificação, estas palavras, na atualidade, estão sendo determinadas por efeitos de sentidos variados, dentre os quais destaca-se o da criminalização. Destaco alguns, como, por exemplo, efeito de ameaça (uma ameaça no social genérica e indistinta), de feiúra e falta de higiene (quando associadas às mulheres de esquerda); de bagunça, balbúrdia, descrédito (quando estas palavras encontram-se referidas à Educação e ao combate à corrupção), de enfrentamento (quando vinculadas às ações policiais em situações de repressão a movimentos sociais), e, ainda, de efeitos que remetem para uma espécie de falta de moral (sobretudo quando vinculadas às diferenças religiosas, à igualdade de gênero, e aos movimentos culturais). Pode-se ler, nas redes sociais, gestos de interpretação (ORLANDI, 1996) que constroem verdades locais (FOUCAULT, 1969) cuja materialidade linguageira tem sede em sítios de significação (ORLANDI, 2001) negativizados, visando convocar a sociedade para uma tomada de posição de negação, aversão e repulsa a qualquer sentido positivo atribuído à palavra comunismo ou de colamento a ideias como sendo esquerda, em geral. Está em jogo, na atualidade, dentre várias práticas, um processo jurídico de criminalização de qualquer ideia ou sujeito que possa estar associado ao que genericamente é denominado de esquerda. ${ }^{1}$

Propomos pensar que uma rede de enunciados nada aleatórios está na base da inflação desse imaginário linguístico (PÊCHEUX, 1988 [1975]). Nossa proposta é descrever aspectos do funcionamento desta rede de enunciados, tomando como base conceitos inaugurais formulados por Pêcheux em 1969. Sem pretender uma análise exaustiva, pretendemos compreender o funcionamento destes enunciados que estão na base dos sítios de significância em torno de comunista, comunismo e esquerda. O corpus discursivo foi organizado a partir de um breve mapeamento desses enunciados e das formas discursivas (PÊCHEUX, 1990 [1969]) comunista, comunismo e esquerda na mídia e em redes digitais.

\section{Os enunciados, as formas discursivas e suas remissões}


$\mathrm{Na}$ primeira parte da obra princeps de Pêcheux, Analyse automathique du discours, publicada em 1969, podemos ler tanto uma crítica ao estado da arte dos estudos da linguagem a partir de Saussure, quanto a formulação de uma proposta de trabalho que desloca a noção de funções da linguagem (em sua tradição funcionalista) para a de funcionamento da linguagem em relação aos processos de produção de sentidos intrinsecamente constituídos nas formações sociais e na história. Com este gesto teórico, aqui compreendido como um acontecimento teórico fundacional no campo dos estudos da linguagem, Pêcheux ao mesmo tempo realiza um gesto político: um deslocamento no modo de ler os textos é também o início de uma intervenção na práxis das ciências sociais. Pêcheux trabalha de modo crítico a metodologia da análise de conteúdo usualmente praticada nas Ciências Sociais, especialmente na Psicologia.

A leitura e a análise precisam estar revestidas teoricamente da compreensão de que um discurso não é algo que se poderia colocar em evidência por si só, pois está remetido a uma série de formas possíveis dos processos de produção em seu movimento dialético. Não se trata de buscar um conteúdo à moda de uma hermenêutica, nem de considerar nos textos um espelhamento da exterioridade sóciohistórica. Para Pêcheux, as condições em que qualquer texto foi produzido são constitutivas do próprio texto, elas estão significando no tecido da materialidade textual, isso não quer dizer, porém, que elas estejam significadas de modo transparente na superfície discursiva. Textos, ou melhor, essa materialidade linguageira que constitui a textualidade, passam a ser tomados como um objeto político, como sede da materialidade dos processos de divisão dos sentidos. Ler tal materialidade linguageira é deparar-se com vestígios dos sintomas de uma época. Em Pêcheux 69, a prática de leitura dos sintomas textuais encontra-se vinculada aos processos de produção e aos efeitos de sentidos em dadas condições de produção.

Pêcheux propõe essa prática de leitura como forma de detectar "sintomas pertinentes do processo de produção dominante que rege o discurso submetido à análise" (Pêcheux, 1990 [1969], p. 105, itálicos do autor). Visando à construção de um dispositivo de análise que leve em conta os vestígios do que é sintomático de um processo de produção de sentidos, Pêcheux propõe um trabalho de desmontagem das superfícies discursivas. Em sua conclusão final e provisória, ele 
afirma: "O móvel desta empreitada é finalmente o de realizar as condições de uma prática de leitura, enquanto detecção sistemática dos sintomas representativos dos efeitos de sentido no interior da superfície discursiva" (PÊCHEUX, op. cit, p. 148, grifos nossos).

Lembremos aqui que o termo "sintoma", utilizado por Pêcheux, pode ser compreendido em relação à "leitura sintomal", expressão formulada por Althusser para referir-se ao modo como Marx lia os textos dos economistas clássicos. Segundo Althusser, esse modo próprio de leitura se apresenta como um dispositivo técnico para ler no texto do outro o jogo entre o dito e o não-dito, entre o que se diz não dizendo, e que estaria nos silêncios, nos equívocos. Leitura de sintomas do que se encontraria velada no movimento de escrita do sujeito, seja pela equivocidade seja pela repetição do que se mostraria, para o pensamento espontâneo, como evidência de sentidos. ${ }^{2}$

Discurso e discursividade, com uma teorização que vai se tornando precisa no correr das páginas iniciais deste primeiro livro de Pêcheux, são termos vinculados conceitualmente a processos de produção de sentidos, relações de e entre sentidos, e(m) suas condições de produção. A expressão formas discursivas corresponde a uma teorização que propõe um engendramento entre linguagem (forma linguística) e condições de produção. De acordo com Pêcheux (1990 [1969], p. 105) "toda forma discursiva particular remete necessariamente à série de formas possíveis" em outras superfícies linguísticas. O jogo de remissões das formas discursivas para diferentes superfícies linguísticas constitui vestígios dos sintomas dos processos de produção do discurso. No movimento da linguagem e das condições de produção, os sentidos são sempre mais de um, produzem efeitos entre interlocutores, variam, deslizam, se enredam; são recalcados ou foracluídos; silenciados, parafraseados, negados, substituídos; colam (por repetição) ou se deslocam (também por repetição); vão (se) agregando e (se) desgarrando; podem produzir adesões, ilusões, rupturas e, mesmo o que se chama de indiferença, também é resultado do movimento dos sentidos e de seus efeitos na história e nos sujeitos, sendo que estes, os sujeitos, estão na história e nos sentidos, sofrendo seus efeitos. Não há história sem produção de sentidos e não há produção de sentidos fora dos processos históricos que constituem uma formação social. E esta relação não é direta, mas deixa vestígios, traços dessas condições de produção. 
A linguagem não é transparente, nem completa, sua autonomia é relativa e os sentidos não são literais, fixos ou presos nas palavras. Os sentidos estão em movimento, são relação $a$, como já foi dito. A Análise do Discurso quer compreender seus processos de produção nas redes de relações que estabelecem entre uns e outros, nas substituições, nas remissões, silenciamentos, e em deslizamentos aparentemente improváveis ou imprevisíveis. Tais movimentos nos processos de produção de sentidos, sua abertura ${ }^{3}$, são compreendidos como inerentes ao próprio funcionamento interno da linguagem em termos do estabelecimento de relações, remissões e substituições entre formas discursivas na ordem do discurso.

Pêcheux chama a atenção para o processo discursivo - sem começo localizável e sem fim discernível - de remissões entre formas linguísticas particulares e outras tantas possíveis tendo em vista a relação constitutiva entre tais processos e os movimentos históricopolítico sociais de reprodução, transformação e possível ruptura nas condições de produção. Tal engendramento constitutivo não tem uma estabilidade, não é homogêneo, não fixa sentidos, e produz efeitos de sentidos igualmente variáveis, mas sempre submetidos às instâncias político-sociais em luta na disputa por hegemonia.

Enquanto base material dos processos discursivos, a linguagem é sede dos efeitos metafórico ${ }^{4}$, ou seja, "do fenômeno semântico produzido por uma substituição contextual" (PÊCHEUX, (1990 [1969], p. 96). Efeito metafórico, portanto, é a noção que designa o movimento dos sentidos, ou seja, das possibilidades de substituição de uma palavra por outra, o que envolve remissões discursivas, silenciamentos, deslizamentos, em dadas condições de produção. A noção de enunciado dá base para se proceder à análise das formas discursivas em relação.

Para Pêcheux (op. cit, pp. 100-104), um enunciado é da ordem do discurso. São os enunciados que fornecem o contexto linguageiro das operações de combinação e substituição entre as formas discursivas. A ligação entre enunciados, por sua vez, tem um funcionamento que extrapola os limites de contiguidade, uma vez que é organizado por domínios semânticos em relação. De acordo com Pêcheux, dois termos podem ser substituídos em dois enunciados, sendo que os dois enunciados pertencentes a dois discursos podem ou não ter interpretações semânticas aproximadas. Tal substituição é dependente 
do efeito de dominância de um processo discursivo. Pêcheux conceitua a dominância discursiva caracterizando-a como responsável pelo processo de produção dominante e pela manifestação de sequências discursivas concretas, tanto as relacionadas ao mecanismo dominante quanto aquelas que ele chama de secundárias, imprevisíveis e aparentemente aleatórias.

Ao descrever o efeito metafórico, Pêcheux (1990 [1969], p. 94, 97) exemplifica as operações de substituição de formas discursivas, considerando, em um dado estado do processo discursivo, duas palavras (ou termos), que tenham uma mesma gramaticalidade, e que possam, ou não, seguir no processo de substituição contextual. $\mathrm{O}$ processo metafórico de substituição incessante de formas discursivas em enunciados produzidos sob o efeito de dominância pode levar a um distanciamento tal que, em função de um recalcamento ou de um silenciamento, perde-se a cadeia de ligações entre o sentido (presumidamente) inicial e os demais. Mas mesmo assim ainda é possível, por definição, reconhecer uma equivalência semântica.

$\mathrm{O}$ que analisaremos a seguir representa um recorte do mecanismo do processo de produção de remissões discursivas em torno de comunismo, comunistas e esquerda considerando a questão: como o deslocamento de sentidos pode afetar o jogo das interpretações e da produção de evidências no todo social?

\section{O comunismo como ameaça: retorno de um efeito de sentido}

Em Mariani (1998), foi feito um longo percurso de análise sobre os sentidos de comunismo e comunista tal como circulavam em jornais cariocas entre 1922 (ano de fundação do Partido Comunista Brasileiro em Niterói) e 1989, ano de candidatura de Roberto Freire do PCB à presidência da república. O levantamento exaustivo então realizado sobre o modo como eram significados os comunistas no discurso jornalístico permitiu compreender que ao longo de décadas ganhou consistência um imaginário polarizado entre o bem (o status quo burguês) e o mal (ou inimigo da pátria, como eram chamados os comunistas). Comunismo e comunista eram termos submetidos a processos de significação negativizados (como falta de apreço pela família, pelos valores pátrios, pela religião católica, dentre outros) e contrários ao que seria a "índole" do brasileiro. Produzindo um efeito de incompreensibilidade para os leitores (como seria possível que um 
brasileiro fosse comunista?), os dizeres sobre os comunistas que circulavam na imprensa tanto impossibilitaram que se tornassem visíveis as contradições sociais, quanto fortaleceram uma direção de sentidos para tornar visível uma certa noção de brasilidade em construção sobretudo a partir dos anos 1920 do século XX.

A imprensa escrita de referência, independentemente da posição discursiva dos jornalistas envolvidos, produziu uma intervenção ao contribuir no apagamento de possíveis rupturas e transformações sociais que a discursividade comunista poderia instaurar. Os rituais enunciativos inerentes à prática jornalística da época, fosse em época de ditaduras, fosse em época de governos democráticos, com suas propriedades discursivas de desambiguização e didatização do mundo, produziram uma homogeneização de dizeres e uma política de silenciamento (ORLANDI, 1992) com efeitos de verdade e literalidade. A análise do corpus permitiu verificar um processo dominante de produção de sentidos que instituiu o PCB no lugar de "inimigo da pátria e da família", "inimigo do Brasil", ou ainda, "mau brasileiro." Durante décadas, nos jornais do Rio de Janeiro, comunismo e comunistas foram substituídos por formas discursivas como maus brasileiros, inimigos da liberdade, inimigos da concórdia, sectários ferozes, inimigos da lei e da pátria, extremistas, doutrina alienígena e ditadura vermelha, dentre outras (MARIANI, 1998, p.124 a 131). Com o PCB na ilegalidade e a discussão política proibida de ser formulada pela maior parte de uma imprensa vinculada ao discurso político conservador e liberal, a forma dominante de discursividade estava voltada para as formas de existência e das cosias-a-saber do mundo capitalista.

Da análise desses 60 anos de discurso jornalístico sobre o PCB, foi possível propor um enunciado definitório: $\mathrm{O} / \mathrm{Um}$ comunista é um/o inimigo nefasto. Este enunciado $O$ comunista é um inimigo, que na historicidade de sua constituição encontra-se inicialmente remetida aos discursos contrários ao movimento anarquista, é parafraseado de várias maneiras em editoriais, em retomada de dizeres outros ou em matérias apresentados como comunistas. Formulados nessa discursividade que polariza e se inscreve no imaginário do bem contra o mal, os efeitos de sentido para comunismo/comunista sustentam, por outro lado, um imaginário de brasilidade a que, majoritariamente, repugna o ideário do materialismo. 
Em Mariani (1998), também foi possível constatar que, pelo trabalho da metáfora discursiva, esse efeito de sentido para comunismo e comunista deslizou para esquerda. Esquerda, esquerdista e esquerdismo em relação com comunismo/comunista são palavras que funcionavam como formas discursivas remissivas substituíveis entre enunciados constituídos anteriormente e os novos, formulados nesse período dos anos 80 do século XX. Assim, 'ser de esquerda' tinha sua referência construída discursivamente pela remissão a 'ser comunista', com os efeitos de sentidos já mencionados.

\section{Um comunista é....um inimigo nefasto.}

Um inimigo nefasto é... um esquerdista.

Nesse mesmo período, mais no início da década de 80, dois outros processos de produção de sentidos estavam em curso e circulavam no discurso jornalístico analisado. Um deles, relacionado à memória dos dizeres da ditadura, fazia incorporar outros sentidos para comunistas e esquerdistas a partir de denominações como "homens sedentos de poder" ou "falsos nacionalistas brasileiros" ou "agitadores esquerdistas, subversivos e antidemocráticos"5. O outro processo em curso de produção de sentidos, mais especificamente durante o período em que houve a queda do muro de Berlim, significava o fim do comunismo com enunciados do tipo "o marxismo acabou" , "bandeiras vermelhas ainda irritam X..." ou com expressões irônicas, como, por exemplo, em "dragõezinhos de esquerda") 6 . Mesmo assim, em 1993, tendo em vista a iminência de eleições presidenciais, manchetes jornalísticas ainda expressavam o sentido de ameaça: “"Perigo vermelho', versão 94. Militares da reserva temem vitória de Lula" (JORNAL DO BRASIL, 20/08, 1993, p. 5. apud MARIANI, 1996). Entre aspas na manchete, perigo vermelho porta como efeito de sentido a memória uma temporalidade passada, remetendo para dizeres e sentidos de uma outra historicidade. Mas, como se sabe, o sentido nunca é apenas um só. Em outras palavras, as aspas na forma discursiva perigo vermelho também produzem eufemismo como efeito de sentido. Seja como memória de uma historicidade que não existiria mais, seja como eufemismo, em perigo vermelho, a evocação da ameaça pela reiteração da forma discursiva torna aquele perigo vermelho ainda materialmente presente, mas como possibilidade em um futuro próximo, tendo em vista a candidatura de Lula, do Partido 
dos Trabalhadores (PT), à presidência da República. Cumpre lembrar que essa manchete não corresponde a um enunciado isolado. Este deslizamento permite-nos pensar no trabalho metafórico em que se mantém um efeito de ameaça aos sentidos atribuídos à brasilidade. Podemos depreender nesse enunciado a dominância de um processo discursivo que produz um efeito de sentido de inimigo ameaçador, formulando um imaginário linguístico repetido durante aproximadamente seis décadas com apoio na imprensa escrita. $\mathrm{O}$ trabalho metafórico está no deslizamento do efeito de sentidos que migra de um partido político específico - $P C B$ - para uma generalização - esquerda $(s)$ - para, em seguida, sua sombra recair sobre outro partido político específico $-P T-\mathrm{e}$, na sequência, em Lula, nome do fundador do partido e candidato à presidência. Vejamos: PCB....Esquerda(s)....PT....Lula....inimigo nefasto.

Na conclusão do livro publicado em 1998, nossa última frase é formulada como uma pergunta: "A eficácia do imaginário construído sobre os comunistas teria chegado ao fim?" (MARIANI, 1998, p. 232). Esta é uma pergunta que nos dias de hoje ganha ares de atualidade. Vinte e um anos depois, durante o período de disputa eleitoral em 2018, mas também após as eleições, reencontramos em enunciados formas discursivas que re-parafraseiam o imaginário de inimigo tomando como referência o par esquerda(s)-PT. Ao mesmo tempo, renovam esses efeitos de sentidos em função da inclusão dos sítios de significância mencionados no início, sobretudo o da criminalização. Vejamos alguns enunciados, selecionados em 2019:

SD1: “... Desta vez nos iríamos ganhar de qq maneira, com Bolsonaro ou com qualquer um outro que se posicionasse a direita desta máfia esquerdista instalada nos quatro cantos da nação. (...)" (via zap, em 03/02/1019, grifos nossos)

SD2: "Se falar do ladrão de nove dedos os demônios vermelhos se manifestam na hora!" (via zap, 18/07/19, grifos nossos)

SD3: "Vejam o que diz o item 9 do decálogo de Lenin!!! "9. Contribua para a derrocada dos valores morais, da honestidade e da crença nas promessas dos governantes. Nossos parlamentares infiltrados nos partidos democráticos devem acusar os comunistas, obrigando-os, sem perda de expô-los ao 
ridículo, a votar somente no que for de interesse da causa socialista." (via zap, em 18/01/19, grifo nosso)

SD4: É sem tirar nem por, exatamente como dizem os PETRALHAS (os que ainda não foram presos) e todo o coletivo DA esquerdalha COMUNISTÓIDE do Brasil. (carta ao presidente, abril, 2019, grifo nosso).

SD5: A CNBB realmente é uma facção comunista dentro da Igreja Católica. (via zap, em 13/08/2019, grifos nossos)

SD6: Urgente! Índios confirmam!! A esquerda bandida e as ONGs estão botando fogo na Amazônia.” (via zap, 26/08/2019, grifos nossos)

Máfia esquerdista / ladrão (de nove dedos) / demônios vermelhos / petralhas / esquerdalha comunistóide / esquerda bandida são sintagmas nominais que em seu funcionamento discursivo remetem a outras formas nominais cuja materialidade está em enunciados anteriores $^{7}$. Tais enunciados anteriores, constitutivos da rede de sentidos de uma memória sobre o comunismo e os comunistas, funcionam como caução para processos de significação do que, na ordem das formações imaginárias, vai sendo construído discursivamente como uma única realidade, sobretudo a partir das eleições de 2018. Além disso, vermelho, comunista e esquerda passam a ser significados, sobretudo, no campo da corrupção e da criminalização.

Enquanto formas discursivas, são substituíveis contextualmente, ou seja, são produto de um processo de produção de sentidos cuja dominância não se inaugura hoje. Lembremos que a dominância discursiva está diretamente relacionada ao processo de produção de sentidos dominante que dá visibilidade à manifestação de sequências discursivas concretas, ou melhor efetivamente em circulação em dado momento histórico. No rastro destes enunciados, o efeito de sentido inimigo nefasto registra, nas superfícies linguísticas em análise, sintomas do retorno de gestos de silenciamento e apagamento do debate político propriamente dito.

Uma diferença importante entre o que foi analisado em Mariani (1998) e o que está sendo analisado agora está no modo de circulação digital desses processos de significação sobre PCB.....comunistas.....esquerda(s).....PT....Lula. Não mais tão 
inseridas no discurso jornalístico, estas formas discursivas remissivas circulam em zaps (e outras redes digitais) organizados por grupos de apoiadores do atual governo. Os zaps se espalham velozmente, entrando em celulares outros, sem pedir licença, uma vez que são repassados e multiplicados por máquinas programadas para tal finalidade. A mídia jornalística impressa ou digital, por sua vez, cita os zaps. Os zaps tornam-se notícia, antecipando o que a mídia irá anunciar, mesmo que seja como comprovantes de circulação de fake news ou de opiniões de grupos extremistas de direita.

Tenho chamado esse modo de circulação das mídias sociais digitais de discursividades prêt-a-porter, pois correspondem a textualidades que circulam prontas para serem vistas, lidas, espalhadas e repetidas sem muita reflexão, ou, em uma palavra, para serem consumidas, descartadas quase instantaneamente e serem substituídas por outras com efeitos de sentidos similares (MARIANI, 2018). A maioria dos zaps, neste funcionamento prê-à-porter, circulam sem autoria, interpelam o outro com um imperativo "repassem" ou "repasse a um amigo(s), colega(s)...", que genericamente representa todos e ninguém. Mesmo quando alguma autoria vem explicitada ("Sou Fulana de tal, dona de casa na cidade X..."), é uma autoria indeterminada (quem seria essa "fulana de tal"?) que interpela o outro. Como afirmei (MARIANI, 2018), a discursividade prêt-à-porter interpela os sujeitos que recebem esses zaps fazendo com que se apropriem subjetivamente deles ao repassá-los. Dizendo de outra forma, em muitos zaps, o anonimato inicial dessas postagens vai sendo subjetivado conforme vão sendo recebidos e repassados por e para sujeitos que supostamente compartilham sentidos. Produz-se, deste modo, uma rede de discursividades que alimenta uma ilusão de consenso. Ou dizendo de outra maneira: no repassar para uns e não para outros, supõe-se uma aliança, um compartilhamento de sentidos entre sujeitos situados em determinadas formações discursivas. No repasse dos zaps, tais sujeitos não apenas estariam tomando posição identificados pela formação discursiva na qual se inscrevem para serem sujeito do que dizem (PÊCHEUX, 1975 [1988], p. 214 e ss.), mas também estariam publicizando de modo eficaz e veloz essa posição. Como afirmei antes, produzindo um efeito de ilusão do consenso, estão em jogo as formações imaginárias (PÊCHEUX, 1990 
[1969]), ou seja, a imagem que o sujeito faz de si, desse outro que lhe enviou o zap e daquele a quem ele reenvia o zap.

Antes de concluir, devo mencionar a circulação da expressão fantasma esquerdopata nessa mídia social digital. Essa expressão fantasma esquerdopata é composta por duas palavras com funcionamento lógico-retórico compreensível quando inserida em uma série remissiva. Tal série remissiva se espraia em mais de uma temporalidade simultaneamente: a da atualidade, a da memória e a do silenciamento, aqui compreendido como uma temporalidade que, em função da censura, coloca em silêncio outros sentidos possíveis.

Fantasma esquerdopata circunscreve na materialidade discursiva as fronteiras de um sítio de significância organizado por um gesto de interpretação bem específico. Entendo que em "fantasma esquerdopata" encontra-se a materialidade de um sítio de significância que condensa várias formas discursivas remissivas. Sem pretender a exaustividade, apresento algumas sequências discursivas recortadas de superfícies discursivas variadas em que fantasma esquerdopata está mencionado. Vejamos:

SD1: “...fantasma esquerdopata que ameaça o futuro do Brasil...." (por zap, em 18/07/19);

SD2: "Margrit Schmidt chama Sigmaringa Seixas, falecido, de "esquerdopata". (Diário do Centro do Mundo, https://www.diariodocentrodomundo.com.br > essencial > irmade-ex-ama..., em janeiro, 2019);

SD3: "Sigmaringa Seixas "esquerdopata" e amigos dele q foram ao ..."(Monica Bergamo, via Twiter, https://www.google.com/search?q=fantasma+esquerdopata\&oq =fantasma+esquerdopata\&aqs=chrome..69i57j33.1410j0j8\&sou rceid=chrome\&ie=UTF-8, em janeiro de 2019);

SD4: "Riobrazil Mudança. Parabéns procurador, vc não tem que dar explicação, acusação sem prova de um fantasma esquerdopata. Só no Brasil." (Portal IG, https://ultimosegundo.ig.com.br > Último Segundo > Política, em janeiro de 2019);

SD5: "Censura: o fantasma que volta a assustar as bibliotecas brasileiras ..promovendo um "discurso esquerdopata" entre os 
alunos, como bem ..."( https://biblioo.cartacapital.com.br > censura-o-fantasma-que-volta-a-assusta. em abril de 2019).

Compreender como os sentidos circulam é compreender o quanto uma forma discursiva, seja ela remissiva ou não, pode estar em um processo de substituição metafórica. Em fantasma esquerdopata é possível depreender uma expressão que relaciona dois termos: fantasma, um termo com sentidos em dispersão e esquerdopata, um neologismo que, em um primeiro gesto de leitura, pode indicar uma síntese da memória de sentidos para comunismo e comunista no Brasil. Mas não apenas isto.

Em seu funcionamento discursivo, tal como pode ser observado nas SDs acima, fantasma esquerdopata e discurso esquerdopata são formas nominais e como tal remetem para algo já sabido dentre as coisas-a-saber no mundo: "Há fantasma esquerdopata". Porém, podese questionar: Fantasma para quem ou para o quê? E o que o neologismo esquerdopata desloca?

Fantasma apresenta como sinonímia possível a forma discursiva espectro, ou seja, fantasma e espectro apresentam possibilidades de substituição em determinados enunciados, em dados contextos. Espectro é um termo que comparece inicialmente em $O$ manifesto comunista, de Marx e Engels (1848), em uma referência direta à presença do comunismo na Europa ${ }^{8}$. Para Pêcheux, tomando o espaço revolucionário como espaço em que se manifestam processos de significação em ruptura e possível transformação, são espectros revolucionários que rondam e assombram a Europa há mais de dois séculos. Os discursos revolucionários, os espectros das revoluções, assombram a estabilidade do sujeito pragmático. No imbricamento da práxis revolucionária com a linguagem, os discursos revolucionários lutam contra o presente visível e apontam para o invisível, para um alhures ainda não-realizado, para um impossível. São discursos que marcam rupturas e transformações com efeitos de sentidos fronteiriços e móveis, e seguem produzindo deslocamentos e direções de sentidos outros para a sociedade na língua. Como nos lembra Pêcheux, a possibilidade de se dizer o invisível e a ausência está na ordem do dizível, na estruturação das línguas: 
Através das estruturas que lhes são próprias, toda língua está necessariamente em relação com o que não está, o que não está mais, o ainda não está, e o nunca estará da percepção imediata: nela se inscreve assim a eficácia omni-histórica da ideologia como tendência incontornável a representar as origens e os fins últimos o alhures, o além, o invisível (Pêcheux, 1990 [1982], p.8).

O fantasma ideológico do comunismo, podemos dizê-lo como sendo um imaginário que assombra o sujeito pragmático uma vez que se encontra além da percepção imediata. Uma fantasmagoria evocada como ameaça de perigo, falada pelo outro e que se encontra revestida por histórias e sentidos vindos de alhures.

Lembremos que Pêcheux (1990 [1982]) teoriza sobre o sujeito pragmático da atualidade, que busca a satisfação de suas necessidades, um mundo logicamente estabilizado, e com uma organização semântica sem equivocidades, organizada com enunciados opositivos e dicotômicos e, em certa medida, coercitivos. Para este sujeito, é imperiosa a necessidade deste mundo semanticamente compreensível e pragmaticamente organizado. Assim, é possível compreender que fantasma, no imaginário linguístico desse sujeito pragmático, designa o que pode desorganizar suas certezas, sua estabilidade em seu mundo. Se há fantasma é porque há algo que ameaça a estabilidade de seu mundo. Ora, esse lugar de fantasma está justamente atribuído à esquerda, que seria capaz de provocar deslocamentos no ordinário de sentidos já estabilizados. Propomos pensar que o efeito fantasmático de ameaça - em fantasma esquerdopata - estaria colado ao efeito de uma memória de ameaça das coisas-a-saber do marxismo como responsáveis pela desmontagem desse mundo lógica, semântica e pragmaticamente estabilizado.

Assim, para além de ser um espectro imaterial, tal como as crenças religiosas propõem, se há fantasma é porque há um ponto de real da história indiscernível, alhures, irrealizado e impossível de ser significado para esse sujeito pragmático que (se) imaginariza (em) uma estrutura sócio-semanticamente estabilizada e homogênea.

A historicidade dos sucessivos apagamentos de uma discussão político-econômico-ideológica consistente vem justamente dar sustentação para esse imaginário fantasmagórico atribuído à esquerda. 
Ao invés de se tentar simbolizar o real (e sabemos que o furo do real resiste à simbolização), ocorre um empobrecimento do simbólico perceptível, na atualidade brasileira, nos xingamentos, na violência verbal, no uso de termos escatológicos como forma de sustentar argumentos, etc. - e uma exacerbação imaginária de um fantasma que se quer eliminar. Lembremos também que foi recorrente, na circulação de zaps durante a campanha presidencial em 2018, de enunciados como "Só penso em exterminar o PT"; "Vamos acabar de vez com esses esquerdistas."

$\mathrm{Na}$ forma discursiva em análise, fantasma está determinado por esquerdopata, um neologismo que funciona em uma série associativa de remissões para dois sítios de significância: o das esquerdas e o da medicina psiquiátrica. Por associação, depreendemos a formação de esquerd (o) pata, como em psicopata: psic (o) pata. A etimologia de psicopata está na união de psyché e pathós, duas palavras gregas que significam alma ou mente, e doença ou sofrimento, respectivamente ${ }^{9}$. Por analogia com a construção de psicopata, podemos compreender que um esquerdopata seria um sujeito doente por ser de esquerda, ou melhor, por pensar como alguém de esquerda. Logo, a ideologia de esquerda seria uma doença. Há, porém, um efeito outro em esquerdopata, efeito ligado à ridicularização e humilhação da ideologia desse sujeito. O neologismo já se encontra em circulação e registrado no Dicionário informal online o qual traz uma definição para esquerdopata: "Esquerdista fanático e doentio contra todas as evidências"". Um esquerdopata seria aquele "contra todas as evidências" justamente aquelas do sujeito pragmático, ou, como define Pêcheux, "cada um de nós, os 'simples particulares' face às urgências de sua vida..." (PÊCHEUX, 1990 [1988], p. 33). A definição acima já porta uma divisão dicotômica de sentidos, já porta a significação de uma posição contra, contrária. Memória dos sessenta anos de sentidos de exclusão para o PCB e para as esquerdas em geral. Nos tempos atuais, a discursividade contra a esquerda assume nos zaps uma forma polarizada com enunciados simplificados, dicotômicos.

Ainda de acordo com o Dicionário informal, são sinônimos para esquerdopata "petralha, esquerdismo, sinistria socialista, comunista, lunático, corruptos, ditadores" e palavras relacionadas são "esquerdista, fanático, lua negra, psicopata, doente, amputação do 
polegar esquerdo, deboche, comunista, ladrões...”. Por outro lado, a rede de antônimos registra: "racional, coerente, à direita, destria, direitista, coxinha, inteligentes, honestos, equilibrados, sensatos, trabalhadores, norma...." Dicionário informal, as formas discursivas remissivas mostram o trabalho da metáfora, que vai produzindo um deslizamento que vai de esquerdista a ladrões..., por um lado, e, de outro, vai de racional a norma. De um lado, o desconhecido, que inspira medo, é merecedor de zombarias ou de prisão, um desconhecido, ou, dizendo de outra maneira, o real indizível e que escapa à lei. De outro, aquele que se enquadra no mundo organizado, racional, honesto, normal... sofrendo as ameaças imaginárias de esquerdopatas multiformes.

Fantasma esquerdopata, enfim, é uma expressão composta por duas palavras com funcionamento lógico-retórico compreensível quando inserida em uma série remissiva. Tal série remissiva se espraia em mais de uma temporalidade simultaneamente: a da atualidade, a da memória e a do silenciamento, aqui compreendida como uma temporalidade que, em função da censura, tenta colocar em silêncio outros sentidos possíveis para esquerda, como já foi dito. Dizer fantasma esquerdopata é tentar colocar em silêncio outros sentidos possíveis.

\section{Considerações finais}

Nas condições de emergência da política brasileira, a partir das eleições de 2018, essa discursividade produzida por ideologias de direita extremamente contrária aos posicionamentos políticos que não sejam os seus vem significando e colocando em circulação uma generalização de tal forma contrária que quaisquer palavras, ideias e práticas, individuais ou coletivas, em instituições públicas ou particulares, que possam, desse ponto de vista, estar associadas ao pensamento de esquerda são incluídas nas mesmas tramas de significação. Engendrando uma discursividade que mescla sentidos vinculados à polícia, à corrupção e à moralidade, sendo regulada pelo discurso jurídico e replicada no discurso político oficial, as palavras comunistas, comunismo e esquerda passam a servir como sentido prêt-à-porter (MARIANI, 2018) para qualquer ideia ou prática que possa ser compreendida como contrária a ideias ultra-conservadoras e ao neoliberalismo. Vem sendo construído um imaginário linguístico 
(PÊCHEUX, 1988 [1975]) inflacionado, polarizado e agudizado, bem alimentado também por políticas de desinformação, ou as chamadas fake news, que circulam nas mídias digitais. É uma discursividade que não polemiza, não reconhece a alteridade nem qualquer tipo de diferença. Ao contrário, encerrada em si mesma, essa discursividade visa produzir uma política de silenciamento (ORLANDI, 1992) em tempos democráticos.

O estudo dos processos discursivos, ou seja, dos processos de significação que têm como base material a língua, como já foi dito, supõe a constituição mútua entre a linguagem (sua materialidade na história) e a historicidade ${ }^{12}$ (em sua materialidade linguageira). Em outras palavras, se falamos em constituição mútua entre linguagem e historicidade é porque o acontecimento de uma palavra, expressão ou texto tomados como discurso é lugar material da produção de sentidos que podem ou não aparecerem como evidentes e óbvios para alguns sujeitos em dada formação social, mas nunca para todos. Dada a complexidade do discurso, tomado como objeto teórico, um trabalho de análise discursiva, precisa situar-se, simultaneamente, em duas ordens de pesquisas: uma voltada para as variações e para as relações entre esses processos de produção de sentidos, e outra que relaciona os processos, suas variações e suas relações com suas condições de produção.

Desse recorte teórico, enfatizamos o movimento dos sentidos tendo em vista o efeito de dominância produzido no interior de um enunciado dado (PÊCHEUX, 1990 [1969]). O processo discursivo de remissões entre formas discursivas particulares e outras tantas possíveis em dadas condições de produção não tem começo localizável (uma data ou lugar preciso) e nem um fim discernível. O sistema de remissões não é qualquer, os sentidos não são abertos para uma polissemia infinita, mas encontram-se regidos por traços dominantes de um dado processo de produção. Aqui se depreende o segundo ponto destacado: uma forma discursiva dada encontra-se em um jogo de remissões com outras formas possíveis, dadas as condições de produção. Neste jogo de remissões entre formas discursivas há vestígios de um processo de produção de sentidos dominante que, como vimos a partir da análise das superfícies linguísticas, podem ser lidos (ou escutados), enquanto sintomas de que 
o sujeito pragmático continua imerso nas evidências de seu pensamento, interpelado pela ideologia e submetido aos seus efeitos.

Tal trama de remissões, com o trabalho da metáfora, constitui o que chamamos de gramática do imaginário linguístico, ou gramática do corpo verbal. Essa gramática funciona na ordem da língua como base linguística de um domínio de sentidos atravessado por um interdiscurso (rede de ditos e não ditos, de silêncios, memória) e sustentado por um intradiscurso marcado com enunciações que formulam posições (com modalizações, ironias, emprego de advérbios, co-referências etc) em determinado temporalidade-espaçosocial. A partir de Pêcheux (1988 [1975]), podemos pensar que as determinações de uma tal gramática na enunciação, enquanto trama produzida pelo interdiscurso em relação com o intradiscurso, atuam no sujeito e induzem à espontaneidade da evidência do pensamento sobre $\mathrm{X}$ / a respeito de $\mathrm{X}$. Como sabemos, não há dominação sem resistência e a evidência do pensamento muitas vezes submerge com a equivocidade, os lapsos que fazem o sujeito tropeçar na língua e se indagar se o sentido não seria outro.

Termino este trabalho de forma provisória. À pergunta formulada em 1998 (“A eficácia do imaginário construído sobre os comunistas teria chegado ao fim?" em MARIANI, 1998, p. 232), e já evocada neste texto, faço outra: Como resistir a esta eficácia da violência simbólica do outro? Como resposta possível e provisória, posso dizer que foi com a escrita do presente artigo que encontrei uma forma de luta.

\section{Referências bibliográficas}

FEU, F. (2008). O sujeito no discurso: Pêcheux e Lacan. Tese de doutorado. Belo Horizonte: Programa de PG em Linguística.

MARIANI, B. (2018). Discursividades prêt-à-porter, funcionamento de fake news e processos de identificação. Entremeios. Revista de estudos do discurso. Volume 17. UNIVAS: Universidade do Vale do Sapucaí, jul/dez.

MARIANI, B. (1998). O PCB e a imprensa. Os comunistas no imaginário dos jornais. Campinas, Rio de Janeiro: Editora da UNICAMP \& Editora Revan. 
MARX, K.; ENGELS, F. (1998). "Manifesto do Partido Comunista". In: Revista Estudos avançados. Dossiê Manifesto comunista. Volume 12, número 34, SP, set./dez. 1998.

ORLANDI, E. (1992). As formas do silêncio no movimento dos sentidos. Campinas: Editora da UNICAMP.

ORLANDI, E. (1996). Interpretação. Autoria, leitura e efeitos do trabalho simbólico. São Paulo: vozes.

ORLANDI, E. (2001). Análise do discurso: princípios e procedimentos. Campinas: Pontes.

Pêcheux, M. (1990). O discurso. Estrutura ou acontecimento. Campinas, Pontes.

PÊCHEUX, M. (1988). Semântica e discurso. Uma crítica à afirmação do óbvio. Campinas: Editora da UNICAMP.

PÊCHEUX, M. (2012). Delimitações, inversões, deslocamentos. Cadernos de Estudos Linguísticos, número 19, 2012, p. 7-24.

PÊCHEUX, M. (1990). "Análise automática do discurso". In: GADET, F.; HAK, T. Por uma análise automática do discurso. Uma introdução à obra de Michel Pêcheux. Campinas: Editora da UNICAMP.

Palavras-chave: Análise do discurso, formas discursivas remissivas, comunismo, comunista, esquerda, mídia social.

Keywords: Discourse Analysis, remissive discoursive forms, communism, communist, left, social midia.

\section{Notas}

* Doutora em Linguística pela Universidade Estadual de Campinas (UNICAMP). É docente da Universidade Federal Fluminense (UFF) e pesquisadora 1C do CNPq.

${ }^{1} \mathrm{Na}$ esfera legislativa, aguardando parecer, há uma proposta de releitura do projeto de lei Lei $7.716(05 / 01 / 89)$, que trata da criminalização do preconceito por raça e por cor, com a inclusão do comunismo.

${ }^{2}$ Feu (2008), em sua tese de doutorado, sintetiza os gestos teóricos de Marx, Althusser e Pêcheux nisso que foi proposto por Althusser como leitura sintomal, afirmando: "A constatação de evidências para o pensamento é, portanto, o sintoma de que alguma coisa permanece velada para esse mesmo pensamento. Assim, o pensamento corre o risco de passar de uma evidência à outra, numa espécie de errância indefinida, quanto mais ele pretende coincidir consigo mesmo identificandose com aquilo que ele enuncia. Contra essa tendência espontânea do pensamento de

Líng. e Instrum. Linguíst., Campinas, SP, n. 44, p. 270-289, jul./dez. 2019 
reproduzir-se indefinidamente é preciso convocar "a suspeita do que falar quer dizer", conforme a fórmula de Althusser, em "Lire le Capital", frequentemente citada por Pêcheux." (FEU, 2008, p. 45).

3 Orlandi (1996) teoriza sobre a "abertura do simbólico", apontando para fronteiras móveis e disjuntas entre polissemia e paráfrase, fronteiras nem sempre definidas, precisas ou definíveis

${ }^{4}$ Uma observação a ser feita: o termo metáfora, em Pêcheux, neste livro, não vem associado diretamente a Lacan, mas podemos reter aqui alguns apontamentos da psicanálise que são pertinentes ao que se está apresentando. Nas palavras de Lacan, a leitura do inconsciente é a realização de uma escuta do sujeito, em transferência analítica, para além do que se ouve. O sujeito do inconsciente é representado e determinado pelo enodamento significante. $\mathrm{E}$ os significantes, autônomos e disjuntos dos significados, representam o sujeito que se encontra às vezes 'parado', às vezes 'em movimento', sendo representado de um significante para outro. Processos metafóricos, em Lacan, são processos de substituição significante, e constituem a lógica do funcionamento do inconsciente. Essas substituições não são conscientes e suas manifestações são enigmáticas para o sujeito. Um processo de análise permite ao sujeito fazer sempre novas associações significantes, perceber-se neste processo para aos poucos tentar compreender o enigma do seu sintoma.

${ }^{5}$ Cf. Mariani (1998, p.195 a 218).

${ }^{6}$ Cf. Mariani (1998, p. 219, 220, 221).

${ }^{7}$ Pêcheux refere-se a "enunciado anterior / enunciação anterior como caução" quando discute as formas nominais e os pronomes que as substituem (PÊCHEUX, 1972 [1969], p. 113).

8 "Um espectro ronda a Europa - o espectro do comunismo." (MARX e ENGELS, $1998[\mathrm{XX}])$.

${ }^{9}$ Cf. Houaiss.

${ }^{10}$ https://www.diconarioinformal.com.br/esquerdopata/ (consulta em 30/08/2019)

11 Dicionário informal, idem.

12 Termo proposto por Orlandi (1996) para situar o trabalho dos sentidos no texto, visando desautomatizar, desta maneira, a proposta conteudística de que haveria uma ligação direta ou de causa e efeito entre acontecimentos históricos e a linguagem. 